aspect of overhead lines applies to France only; but their remarks on wayleave, compensation to landowners, organisation of working parties, establishment of work-places for the manufacture of ferroconcrete masts at various parts of the line, the transport of these masts, their erection, and other matters of an administrative nature, is well worth reading, and is, with but slight modifications, also applicable to similar work when done in this country.

\section{GISBERT KAPP.}

\section{OUR BOOK SHELF.}

Facts and Fallacies regarding the Bible. By W. Woods Smyth. Pp. $\mathrm{x}+208$. (London : Elliot Stock, 19II.) Price $3 s .6 d$. net.

Mr. Woods SMYTH aims at showing that modern scientific knowledge is in agreement with Divine revelation as recorded in the Bible. He considers that the Mosaic account of the creation of worlds and of the various forms of life up to man should be accepted as an authoritative and accurate statement of inorganic and organic evolution. "The sober truth is," he says, "that wherever the Bible touches upon questions of science it does so with a grace, an accuracy, and a philosophic perfection which surpasses every text-book of science in existence."

This position is clear enough, and we cannot but admire the author for his courage in occupying it in spite of the difficulties involved. We believe, however, that he will not find supporters among theologians who know most of the origin of the Scriptures or among philosophers who are best acquainted with the facts of nature. I.f all scientific knowledge and theory of to-day can be shown to be only a confirmation of the Biblical record, what will be said a hundred years hence, and what was the case in the time of early Greek philosophers? Science is progressive, and the accepted views of one generation become the discarded lumber of another.

Unless, therefore, the Bible is regarded as containing all scientific knowledge for all time, there is not much purpose in showing that science and revelation are in agreement at a particular epoch, even assuming this to be the case. A more reasonable view to take is that the Scriptures are faithful historical records of what was thought or believed when they were compiled, containing observations of obvious phenomena only, and interpretations appropriate to the period in which they were made. Any attempt to show that the facts of modern science can be confirmed by reference to an inspired literature must depend upon special pleading for its case, and can do little to further the desire "to restore the Bible to its high place of authority by restoring faith in the subject-matter of the Divine revelation."

"I Wonder" Essays for the Young People. By the writer of "Confessio Medici." P p. Iog. (London : Macmillan and Co., Ltd., Igrr.) Price $3 s .6 d$. net. THE young people to whom the author refers on the title-page of this book must be of a metaphysical frame of mind to be able to read these essays with interest and intelligence. The subtle reasoning occasionally involved requires careful thought for its comprehension, and is best appreciated by the adult philosopher. A fine distinction on the use of the verb "to wonder" is made in the first essay. "Make up your mind," says the author, "that you will only wonder at," and do not wonder if, is, when, or where. But the verb signifies to doubt or expect as well as to marvel; so that the advice given need not be talien literally. There is a useful lesson in the second NO. 2 I59, VOL. 86$]$ essay, which aims at showing that many attributes of things exist only so far as our senses are able to appreciate them; but it will be lost on most young people. Other essays deal with the wonder of nature, of self, of pain, of death, of beauty, and the use of wonder.

It is scarcely correct to say that "there are gases to which the air is as paving-stones to. feathers," or that the something-signifying the ether-which exists throughout space "is one and the same energy, manifest in all things." If, as the author says, "it takes a fellow of the Royal Society to think of the interstellar ether," it may be said with equal approach to accuracy that membership of the Aristotelian Society is desirable to appreciate the points of some of his essays. The book has, however, the merit of fine style and noble thought, and provides an admirable antidote to the influence of overmuch attention to materialistic affairs. Das biologische Schullaboratorium. By Dr. W.
Schoenichen. Pp. 67. (Leipzig: Meyer, I910.) Price 1.6o marks.

IN this pamphlet Dr. Schoenichen gives an interesting account of the structural arrangements, equipment, and course of study in the biological department at the Helmholtz "Realgymnasium" in Schöneberg. The author passes rather lightly by the courses of general zoology and botany, though there is abundant internal evidence that these subjects are accorded a generous and judicious treatment. His main purpose appears rather to be to lay stress upon the hygienic value of biological study as a subject of general education. In this country a certain hazy conception of spores, germs, bacilli, bacteria percolates through the medium of the daily Press into the mind of the man in the street, but neither he nor his wife has any real knowledge of the "why" and the "how" of personal or domestic hygiene. About half of the present treatise is more or less directly concerned with this aspect of biology, and accordingly we find full accounts of a few of the more common species of moulds, of nutrient media, and the various appliances employed in connection with them; of the process of sterilisation and the production of "pure" cultures. A prominent place and full description are given of Prof. Lindner's ingenious " roll-cylinders," and of their employment in the biological analysis of air, water, \&c., and his method of "drop-culture" is well explained and illustrated.

The concluding pages are devoted to a brief survey of the biological courses at ten of the German universities.

What will the Weather Be? The Amateur Forecaster's Vade Mecum. By H. G. Busk. Pp. 27. (Cambridge: W. Heffer and Sons, Ltd.; London: Simpkin, Marshall and Co., Ltd., I9II.) Price $6 d$. net.

This little manual is intended to enable the nonscientific reader to forecast the weather, for a day in advance, from his own observations. Tables arranged under the principal wind directions show the average conditions of weather to be expected in winter and summer, with changes of barometrical pressure. The work is accompanied by a useful introduction by $\mathrm{Mr}$. H. B. Stone, explaining the usual sequence of weather in areas of high and low atmospherical pressure; it is this principle that lies behind the tables, and may enable a forecaster to obtain "reasonable accuracy" by their use. More accurate forecasting depends upon the tracks actually being taken by crclonic disturbances and other considerations, including the configuration of the ground. 